\title{
Faktor-Faktor yang Mempengaruhi Produktivitas Tenaga Kerja berdasarkan Sistem Pemberian Upah Borongan di Kabupaten Sampang (Studi Kasus Pembangunan ICU RSUD Kabupaten Sampang)
}

\author{
Factors Affecting Workers Productivity based on Lumpsum Salary \\ System in Sampang Regency (Case of Constructon of the ICU of \\ Public Regency Hospital in Sampang Regency)
}

\author{
Moch. Hazin Mukti ${ }^{1, a)}$ \& Dedy Asmaroni ${ }^{1, b)}$ \\ ${ }^{1)}$ Teknik Sipil, Fakultas Teknik, Universitas Madura, Pamekasan. \\ Koresponden : a)hazinmukti1@gmail.com \& b) dedyasmaroni@unira.ac.id
}

\begin{abstract}
ABSTRAK
Perkembangan teknologi sangat berpengaruh terhadap kemajuan di berbagai aspek khususnya di bidang konstruksi. Persaingan bisnis yang semakin ketat antar perusahaan jasa pelaksanaan konstruksi (kontraktor) memicu para pelaku usaha untuk berlombalomba memberikan pelayanan atas kepuasan pelanggan. Oleh sebab itu sangat penting bagi perusahaan untuk memperhatikan produktivitas tenaga kerjanya. Dengan upah yang sesuai akan memberikan kepuasan dan semangat kerja pekerja yang dapat meningkatkan produktivitasnya sehingga perusahaan pun mendapatkan hasil yang optimal. Berdasarkan latar belakang yang telah diuraikan, akan dilakukan penelitian tentang faktor-faktor yang mempengaruhi produktivitas tenaga kerja konstruksi borongan. Metode penelitian yang digunakan dalam penelitian kali ini adalah metode analisa statistik deskriptif yaitu dengan mengumpulkan data primer dan data sekunder. Data primer merupakan data yang diperoleh langsung dari sumber pertama seperti wawancara dan pengisisan kuesioner, sedangkan data sekunder merupakan jenis data yang diperoleh dari sumber kedua seperti uji literature atau tinjauan pustaka. Pengujian ini menggunakan pengujian Kruskall Wallis. Dari data diketahui bahwa pada empat variabel masing-masing dengan sampel berjumlah 32 memiliki mean ranks berturut-turut yaitu 27,25 pada variabel X1 (kecepatan kerja), 84,81 pada variabel X2 (kerjasama), 84,94 pada variabel X3 (semangat kerja) dan 61,00 pada variabel X4 (loyalitas kerja).
\end{abstract}

Kata Kunci : manajemen aset infrastruktur, pembangunan infrastruktur, proyek, upah, produktivitas kerja.

\section{PENDAHULUAN}

Infrastruktur sebagai kebutuhan pokok suatu wlayah harus dikelola dengan baik, agar selalu bisa berfungsi, secara ekonomis, efektif dan efisien (Suprayitno \& Soemitro, 2018). Dalam sklus hidup infrastruktur, langkah pembangunan infrastruktur memakan biaya yang tinggi, dibanding langkah-langkah yang lain. Oleh karena itu, kontrol yang baik terhadap biaya pembangunan menjadi sangat penting. Sehingga produktivitas tenaga kerja dalam pembangunan merupakan faktor yang penting dalam kontrol biaya.

Perkembangan teknologi sangat berpengaruh terhadap kemajuan di berbagai aspek khususnya di bidang konstruksi. Persaingan bisnis yang semakin ketat antar perusahaan jasa pelaksanaan konstruksi (kontraktor) memicu para pelaku usaha untuk berlomba-lomba 
memberikan pelayanan atas kepuasan pelanggan. Oleh sebab itu sangat penting bagi perusahaan untuk memperhatikan produktivitas tenaga kerjanya.

Salah satu faktor yang mempengaruhi produktivitas tenaga kerja adalah upah. Upah merupakan segala sesuatu yang diterima oleh pekerja sebagai tanda balas jasa atas suatu pekerjaan terhadap perusahaan. Berdasarkan UndangUundang Kecelakaan Tahun 1974 Nomor 33 Pasal 7 upah adalah pembayaran berupa uang, makan, tempat tinggal yang didapat buruh sebagai ganti bekerja. Anoraga (1998) menyatakan bahwa pada dasarnya seseorang bekerja mengharapkan imbalan yang sesuai dengan jenis pekerjaannya. Dengan adanya upah yang sesuai, maka akan timbul gairah kerja yang tinggi untuk dapat memenuhi kebutuhan hidupnya dan merasa dirinya dibutuhkan oleh perusahaan dalam kelangsungan usahanya, sehingga pada akhirnya akan menimbulkan terjalinnya hubungan timbal balik yang sesuai. Dengan upah yang sesuai akan memberikan kepuasan dan semangat kerja pekerja yang dapat meningkatkan produktivitasnya sehingga perusahaan pun mendapatkan hasil yang optimal.

Sistem pemberian upah tersebut dapat memberikan pengaruh yang besar terhadap produktivitas tenaga kerja. Asmaroni (2014), Hasibuan (2000: 126), Tanto dkk (2012), Rasio (2015), dan Sedarmayanti (2001) mengatakan bahwa "ada hubungan antara sistem pemberian upah dengan produktivitas tenaga kerja". Sedangkan yang dimaksud dengan produktivitas kerja itu sendiri adalah kemampuan untuk memperoleh manfaat yang sebesar-besarnya dari sarana dan prasarana yang telah disediakan sehingga menghasilkan output yang optimal, bahkan hasil yang maksimal. Secara umum produktivitas dirumuskan sebagai perbandingan antara output (pengeluaran) dengan input (pemasukan). Apabila produktivitas naik maka efisiensi (waktu, bahan, tenaga), sistem kerja, teknik produksi, dan keterampilan tenaga kerja juga akan meningkat.

Berdasarkan latar belakang yang telah diuraikan, akan dilakukan penelitian tentang faktor-faktor yang mempengaruhi produktivitas tenaga kerja konstruksi borongan. Metode penelitian yang digunakan dalam penelitian kali ini adalah metode analisa statistik deskriptif yaitu dengan mengumpulkan data primer dan data sekunder.

\section{METODE PENELITIAN}

\section{Tempat Penelitian dan Responden}

Penelitin ini dilakukan akan dilaksanakan pada Pembangunan ICU RSUD Kabupaten Sampang. Penelitian ini berlokasi di wilayah Kecamatan Sampang, Kabupaten Sampang. Pada penelitian ini dilakukan pengamatan tentang perbandingan faktor-faktor yang mempengaruhi produktivitas buruh konstruksi borongan. Pengambilan data dilakukan pada saat jam kerja. Dalam penelitian ini, responden utama penelitian ditujukan kepada buruh konstruksi pada pembangunan gedung ICU di RSUD Kabupaten Sampang dengan jumlah sampel sebanyak 32 responden. Adapun rincian dari 32 sampel tersebut adalah dijelaskan dalam Tabel 1 dibawah.

Tabel 1. Rincian Responden

\begin{tabular}{clc}
\hline No & \multicolumn{1}{c}{ Keterangan } & Jumlah \\
\hline 1 & KPA & 1 \\
2 & PPK & 1 \\
3 & PPTK & 1 \\
4 & Konsultan Pengawas & 3 \\
5 & Kontraktor & 1 \\
6 & Mandor & 5 \\
7 & Tukang/Pekerja & 20 \\
\hline Jumlah & 32 \\
\hline
\end{tabular}


Metode penelitian yang digunakan dalam penelitian ini adalah metode penelitian dengan statistika inferensial dengan menggunakan data hasil survei. Statistika inferensial merupakan statistik yang mencakup semua metode yang berhubungan dengan analisa sebagian data untuk kemudian sampai pada peramalan atau penarikan kesimpulan mengenai keseluruhan gugus data induknya (Waldpole, 1995).

\section{Teknik Pengumpulan Data}

Teknik pengumpulan data diperoleh dari data primer secara langsung guna mencapai tujuan penelitian. Ada beberapa cara yang digunakan, yaitu sebagai berikut.

1. Wawancara, yaitu proses tanya jawab sepihak kepada objek yang bersangkutan yaitu kepada pihak kontraktor dan tenaga keja yang bersangkutan.

2. Angket kuesioner, yaitu sarana yang dilakukan dengan pengisian daftar pertanyaan oleh responden secara langsung guna mendapatkan informasi yang dibutuhkan dalam penelitian. Angket dapat dibedakan menjadi 2, yaitu angket dengan pertanyaan tertutup serta angket dengan pertanyaan terbuka. Kuesioner diberikan kepada buruh konstruksi di RSUD Kabupaten Sampang.

3. Observasi, merupakan teknik pengumpulan data dengan cara merekam fenomena yang terjadi secara langsung suatu keadaan atau situasi.

\section{Identifikasi Variabel Penelitian}

Dalam pengambilan variabel, terlebih dahulu menggunakan metode survey ke lokasi untuk mengetahui apakah variabel yang akan dipilih dapat berpengaruh atau tidak apabila digunakan di lokasi tersebut. Setelah melakukan survey lokasi dan meninjau penelitian terdahulu yaitu Lazib, dkk (2010). "Konsep Tentang Pemberian Upah Terhadap Produktivitas Buruh Konstruksi di Surabaya", dari penelitian tersebut terdapat variabel kedisiplinan, presensi, semangat kerja, kuantitas pekerjaan, dan kualitas pekerjaan. Pada penelitian yang dilakukan Rachman \& Utomo (2011). "Perbandingan Sistem Pemberian Upah Harian dengan Upah Borongan Terhadap Produktivitas Buruh Konstruksi Pada Kontraktor di Surabaya", dari penelitian tersebut terdapat variabel tingkat absensi yang tinggi, kualitas pekerjaan yang baik, kerjasama yang baik, kecepatan kerja yang tinggi, semangat kerja yang tinggi, kreatifitas pekerjaan yang tinggi, tanggung jawab pekerjaan yang tinggi. Jadi dari penelitian terdahulu dapat ditemukan variabel yang sesuai untuk diterapkan di lokasi tersebut, antara lain: kecepatan kerja, kerjasama, semangat, loyalitas pekerjaan. Oleh karena itu variabel yang digunakan dalam penelitian ini yaitu variabel bebas (X) yang terdiri dari X1. kecepatan kerja, X2. kerjasama, X3. semangat dan X4. loyalitas pekerjaan sedangkan variabel terikat (Y) terdiri dari produktifitas.

\section{Metode Statistik Inferensial}

Statistika inferensia adalah statistik yang mencakup semua metode yang berhubungan dengan analisa sebagian data untuk kemudian sampai pada peramalan atau penarikan kesimpulan mengenai keseluruhan gugus data induknya. (Waldpole, 1995). Berikut merupakan konsep atau pengertian-pengertian mengenai penggunaan metode statistik inferensia menurut Setiawan (2005) dan Kukuh (2015) antara lain :

\section{Validitas}

Istilah validitas berhubungan dengan kriteria hasil pengukuran. Pada umumnya, validitas dipermasalahakan pada pengukuran-pengukuran non fisik, seperti dalam pengukuran, sikap dan minat.

2. Reliabilitas

Istilah reliabilitas berhubungan dengan kriteria alat pengukuran. Misalnya untuk mengukur minat, sehingga kita memperoleh angka-angka skor untuk menyatakan 
minatnya rendah, minatnya sedang, atau minatnya tinggi, alat pengukuran yang menghasilkan skor-skornya tersebut sering dipermasalahkan.

3. Pengujian Hipotesa

Hipotesa merupakan dugaan sementara yang masih perlu diuji kebenarannya. Terdiri beberapa jenis hipotesa dalam melakukan penelitian dan berikut langkah-langkah pengujian hipotesa.

- Menentukan parameter yang akan diuji (proporsi, rata-rata, koefisien korelasi, dll)

- Terjemahkan dugaan penelitian kedalam pasangan hipotesis statistik $\mathrm{H}_{0}$ dan $\mathrm{H}_{1}$.

- Tentukan taraf nyata (level of significance 5\%) atau a yang akan digunakan dalam pengujian.

- Pengumpulan data melalui sampel acak $\mathrm{n}$.

- Pilih Uji Statistik yang tepat berdasarkan studi kasus yang tentukan.

- Tentukan daerah dan titik kritis pengujian.

- Lakukan pengujian untuk menolak atau menerima $\mathrm{H}_{0}$.

- Tentukan atau hitung nilai p yaitu nilai peluang kekeliruan untuk menolak $\mathrm{H}_{0}$ yang benar.

- Tarik kesimpulan statistik.

4. Uji Kruskal-Wallis (Analisis Varian Ranking Satu Arah)

Pengujian ini berfungsi untuk menguji perbedaan nilai tengah populasi berdasarkan nilai tengah dari k sampel yang tidak berpasangan, syarat penggunaan pengujian ini yaitu data berskala ordinal. Rumus yang dipakai sebagai berikut :

$$
\begin{aligned}
& H=\frac{12}{\mathrm{~N}(\mathrm{~N}+1)} \sum_{\mathrm{j}-1}^{\mathrm{k}} \frac{\mathrm{R}_{j-1}^{2}}{\mathrm{n}_{j}}-3(\mathrm{~N}+1) \\
& I=\frac{\sum T}{N^{3}-N} \\
& \mathrm{H}=\frac{\frac{12}{N(N+1)} \sum_{j-1}^{k} \frac{R_{j-1}^{2}}{n_{j}}-3(N+1)}{\frac{\sum T}{N^{3}-N}}
\end{aligned}
$$

\section{HASIL PENELITIAN}

\section{Pengujian Kesesuaian Skor Dengan Standar (Validitas)}

Uji validitas digunakan untuk mengetahui kevalidan angket dalam mengumpulkan data. Pengujian kesesuaian skor dengan standar dilakukan pada 4 variabel menggunakan software SPSS.

- Data Informasi Statistik Kecepatan Kerja (X1)

Tabel 2 merupakan hasil rekapan pearson correlate pada data informasi statistik

\begin{tabular}{|c|c|c|c|c|c|}
\hline Pettanyaa & Comelate & & ITabel & Keputusan & Kesimpulan \\
\hline X1.1 & 16 & & 0.3 & $\mathrm{arma} \mathrm{HO}$ & Data yan. \\
\hline$X 1.2$ & 0.0 & & 0.344 & Terima HO & Data yang dipe \\
\hline
\end{tabular}
kecepatan kerja (X1) menggunakan software SPSS.

Tabel 2. Data Informasi Statistik Kecepatan Kerja (X1)

Tabel 2 merupakan tabel hasil pengujian validitas kecepatan kerja (X1) menggunakan software SPSS. Dari data kecepatan kerja (X1), pertanyaan X1.1 dan X1.2 diperoleh nilai pearson correlate yaitu 0,816 . Nilai tersebut lebih besar dari $r$ tabel yaitu 0,344 sehingga dapat diputuskan bahwa data terima hipotesa nol dan kesimpulannya yaitu data yang diperoleh telah valid. 
- Statistik Data Informasi Kerjasama Pekerja (X2)

Tabel 3 merupakan hasil rekapan pearson correlate pada data informasi statistik variabel kerjasama (X2) menggunakan software SPSS.

Tabel 3. Data Informasi Statistik Kerjasama (X2)

\begin{tabular}{cccccc}
\hline Pertanyaan & Pearson Correlate & $\iota$ & rTabel & Keputusan & Kesimpulan \\
\hline X2.1 & 0.812 & $\geq$ & 0.344 & Terima H0 & Data yang diperoleh telah valid \\
X2.2 & 0.856 & $\geq$ & 0.344 & Terima HO & Data yang diperoleh telah valid \\
\hline
\end{tabular}

Tabel 3 merupakan tabel hasil pengujian validitas kerjasama pekerja (X2) menggunakan software SPSS. Dari data variabel kerjasama (X2) pertanyaan X2.1 dan X2.2 diperoleh nilai pearson correlate yaitu 0,812 . Nilai tersebut lebih besar dari $r$ tabel yaitu 0,344 sehingga dapat diputuskan bahwa data terima hipotesa nol dan kesimpulannya yaitu data yang diperoleh telah valid.

- Data Informasi Statistik Semangat Kerja (X3)

Tabel 4 merupakan hasil rekapan pearson correlate pada data informasi statistik semangat kerja (X3) menggunakan software SPSS.

Tabel 4. Data Informasi Statistik Semangat Kerja (X3)

\begin{tabular}{cccccc}
\hline Pertanyaan & PearsonCorrelate & $\langle\geq$ & r Tabel & Keputusan & Kesimpulan \\
X3.1 & 0.769 & $\geq$ & 0.344 & Terima HO & Data yang diperoleh telah valid \\
X3.2 & 0.824 & $\geq$ & 0.344 & Terima H0 & Data yang diperoleh telah valid \\
\hline
\end{tabular}

Tabel 4 merupakan tabel hasil pengujian validitas semangat kerja (X3) menggunakan software SPSS. Dari data variabel semangat kerja (X3) pertanyaan X3.1 dan X3.2 diperoleh nilai pearson correlate yaitu 0,769 . Nilai tersebut lebih besar dari $r$ tabel yaitu 0,344 sehingga dapat diputuskan bahwa data terima hipotesa nol dan kesimpulannya yaitu data yang diperoleh telah valid.

- Data Informasi Statistik Loyalitas Kerja (X4)

Tabel 5 dibawah ini merupakan hasil rekapan pearson correlate pada data informasi statistik loyalitas pekerja (X4) menggunakan software SPSS.

Tabel 5. Data Informasi Statistik Loyalitas Pekerja (X4)

\begin{tabular}{|c|c|c|c|c|c|}
\hline Pettanyaan & Pearson Correlate & $\langle\geq$ & ITabel & Keputusan & Kesimpulan \\
\hline$X 4.1$ & 0.829 & $\geq$ & 0.344 & Terima HO & Data yang diperoleh telah valid \\
\hline$X 4.2$ & 0.781 & $\geq$ & 0.34 & Terima HO & Data yang diperoleh telah valid \\
\hline
\end{tabular}

Tabel 5 merupakan tabel hasil pengujian validitas pada variabel loyalitas pekerja (X4) menggunakan software SPSS. Dari data loyalitas pekerja (X4) pertanyaan X4.1 dan X4.2 diperoleh nilai pearson correlate yaitu 0,829 . Nilai tersebut lebih besar dari $r$ tabel yaitu 0,344 sehingga dapat diputuskan bahwa data terima hipotesa nol dan kesimpulannya yaitu data yang diperoleh telah valid.

\section{Uji Reliabilitas}

- Data Informasi Statistik Kecepatan Kerja (X1)

Hasil Uji Realibilitas unutk variable Keceparan Kerja (X1) disampaikan pada Tabel 6 sebagai berikut. 
Tabel 6. Cassing Processing Summary

\begin{tabular}{llrc}
\hline \multicolumn{4}{l}{ Case Processing Summary } \\
\hline \multicolumn{3}{c}{$\mathrm{N}$} & $\%$ \\
\hline Cases & Valid & 32 & 100 \\
& Excludeda & 0 & 0 \\
\hline & Total & 32 & 100 \\
\hline
\end{tabular}

Tabel 6 merupakan tabel cassing processing summary yang menunjukkan data uji dalam bentuk tabel. Dari data diperoleh informasi bahwa data yang sampel yang diuji berjumlah 32 dengan tingkat valid $100 \%$.

Tabel berikut merupakan hasil pengujian reliabilitas pada variabel kecepatan kerja (X1).

Tabel 7. Hasil Uji Realibilitas Kecepatan Kerja (X1)

\begin{tabular}{|c|c|}
\hline \multicolumn{2}{|c|}{ Reliability Statistics } \\
\hline Cronbach's & $\mathrm{N}$ of Item \\
\hline 0.5 & 2 \\
\hline
\end{tabular}

Tabel 7 merupakan tabel hasil pengujian reliabilitas yang menunjukkan nilai cronbach's alpha. Dari data diperoleh informasi bahwa cronbach's alpha sebesar 0,500. Nilai tersebut lebih besar dari $\mathrm{R}$ tabel yaitu 0,344 maka dapat diputuskan bahwa data pada variabel kecepatan kerja telah reliable (konsisten). Dan nilai berada dalam interval 0,4000,599, maka masuk dalam kriteria cukup.

- Data Informasi Statistik Kerjasama Pekerja (X2)

Tabel 8 berikut merupakan hasil pengujian reliabilitas pada variabel Kerjasama Pekerja (X2).

Tabel 8. Hasil Uji Realibilitas Kerjasama (X2)

\begin{tabular}{|c|c|}
\hline \multicolumn{2}{|c|}{ Reliability Statistics } \\
\hline $\begin{array}{c}\text { Cronbach's } \\
\text { Alpha }\end{array}$ & $\mathrm{N}$ of Item \\
\hline 0.56284153 & 2 \\
\hline
\end{tabular}

Tabel 8 merupakan tabel hasil pengujian reliabilitas yang menunjukkan nilai cronbach's alphsa. Dari data diperoleh informasi bahwa cronbach's alpha sebesar 0,563. Nilai tersebut lebih besar dari $\mathrm{R}$ tabel yaitu 0,344, maka dapat diputuskan bahwa data pada variabel kerjasama (X2) telah reliable (konsisten). Dan nilai berada dalam interval 0,4000,599, maka masuk dalam kriteria cukup.

- Data Informasi Statistik Semangat Kerja (X3)

Tabel 9 berikut merupakan hasil pengujian reliabilitas pada variabel Semangat Kerja (X3).

Tabel 9. Hasil Uji Realibilitas Semangat Kerja (X3)

\begin{tabular}{cc}
\hline \multicolumn{2}{c}{ Reliability Statistics } \\
\hline Cronbach's Alpha & N of Item \\
0.425149701 & 2 \\
\hline
\end{tabular}

Tabel 9. merupakan tabel hasil pengujian reliabilitas yang menunjukkan nilai cronbach's alpha. Dari data diperoleh informasi bahwa cronbach's alpha sebesar 0.425. Nilai tersebut lebih besar dari nilai $\mathrm{R}$ tabel yaitu 0,344, maka dapat diputuskan bahwa data telah reliable (konsisten) pada data informasi statistik semangat kerja (X3). Dan nilai berada dalam interval 0,400-0,599, maka masuk dalam kriteria sangat cukup. 
- Data Informasi Statistik Loyalitas Kerja (X4)

Tabel 10 berikut merupakan hasil pengujian reliabilitas pada variabel Loyalitas Kerja (X4).

Tabel 10. Hasil Uji Realibilitas Loyalitas Kerja (X4)

\begin{tabular}{cc}
\hline \multicolumn{2}{c}{ Reliability } \\
\hline Cronbach's \\
Alpha & Nof Item \\
0.457142857 & 2 \\
\hline
\end{tabular}

Tabel 10 merupakan tabel hasil pengujian reliabilitas yang menunjukkan nilai cronbach's alpha. Dari data diperoleh informasi bahwa cronbach's alpha sebesar 0,457. Nilai tersebut lebih besar dari nilai $\mathrm{R}$ tabel yaitu 0,344 , maka dapat diputuskan bahwa data telah reliable (konsisten) pada data informasi statistik loyalitas kerja (X4). Dan nilai berada dalam interval 0,400-0,599, maka masuk dalam kriteria cukup.

- Rekap Uji Reliabilitas

Rangkuman Hasil Uji Realibilitas disampaikan pada Tabel 11 sebagai berikut.

Tabel 11. Hasil Rekapan Uji Reliabilitas

\begin{tabular}{cccc}
\hline Variabel & Cronbach's Alpha & r tabel 5\% (32) & Keterangan \\
\hline X1 & 0,500 & 0,344 & Reliabel \\
X2 & 0,563 & 0,344 & Reliabel \\
X3 & 0,425 & 0,344 & Reliabel \\
X4 & 0,457 & 0,344 & Reliabel \\
\hline
\end{tabular}

Dari hasil Reliabilitas diperoleh nilai Cronbach's Alpha pada Tabel 11 untuk semua variabel lebih besar dari nilai $r$ tabel. Sehingga dapat disimpulkan bahwa semua data responden dalam penelitian dinyatakan Reliabel (konsisten). Oleh sebab itu, data dapat digunakan sebagai instrumen penelitian.

\section{Uji Kruskall Wallis}

Uji Kruskall Wallis dilakukan untuk membandingkan keempat data variabel. Pengujian dilakukan menggunakan SPSS dengan menggunakan teknik statistik non parametrik.

Perhitungan manual variabel berdasarkan indikator-indikator yang ditentukan.

$$
\begin{aligned}
& H=\frac{12}{128(128+1)} \times\left[\frac{R 1^{2}}{32}+\frac{R 2^{2}}{32}+\frac{R 3^{2}}{32}+\frac{R 4^{2}}{32}\right]-3(128+1) \\
& H=\frac{12}{128 \times 129} \times\left[\frac{27,25^{2}}{32}+\frac{84,81^{2}}{32}+\frac{84,94^{2}}{32}+\frac{61,00^{2}}{32}\right]-3(129) \\
& H=\frac{12}{16512} x\left[\frac{742,563}{32}+\frac{7192,736}{32}+\frac{7214,804}{32}+\frac{3721}{32}\right]-3(129) \\
& H=\frac{12}{16512} \times[23,205+224,773+225,463+116,281]-3(129) \\
& \mathrm{H}=0,000728 \times 589,722-387 \\
& \mathrm{H}=57123
\end{aligned}
$$

- Uji Kruskall Wallis 4 Variabel

Berikut ini Tabel 12 yang merupakan hasil pengujian statistika non parametrik menggunakan uji Kruskall Wallis. 
Tabel 12. Hasil Ranks Uji Kruskall Wallis Informasi 4 Variabel

\begin{tabular}{clcc}
\hline \multicolumn{3}{c}{ Ranks } \\
\hline \multicolumn{1}{c}{ Grup } & N & Mean Rank \\
\hline Variabel & Kecepatan Kerja & 32 & 27.25 \\
& Kerjasama & 32 & 84.81 \\
& Semangat Kerja & 32 & 84.94 \\
& Loyalitas Kerja & 32 & 61.00 \\
& Total & 128 & \\
\hline
\end{tabular}

Tabel 12 merupakan hasil pengujian Kruskall Wallis yang menunjukkan deskriptif dari data yang diuji. Dari data diketahui bahwa pada empat variabel masing-masing dengan sampel berjumlah 32 memiliki mean ranks berturut-turut yaitu 27,25 pada variabel X1 (kecepatan kerja), 84,81 pada variabel X2 (Kerjasama), 84,94 pada variabel X3 (Semangat kerja) dan 61,00 pada variabel X4 (loyalitas kerja).

Berikut ini merupakan tabel hasil pengujian statistika non parametrik menggunakan uji Kruskall Wallis.

Tabel 13. Hasil Uji Kruskall Wallis Informasi 4 Variabel

\begin{tabular}{lc}
\hline & Test Statistics a,b \\
\hline & Variabel \\
\hline Chi-Square & 57.123 \\
df & 3 \\
Asymp. Sig. &, 000 \\
\hline
\end{tabular}

Tabel 13 merupakan tabel hasil pengujian Kruskall Wallis pada yang menunjukkan nilai Chi-Square, $d f$ dan Asymp.sig berturut-turut sebesar 57,123, 3 dan 0. Nilai signifikan kurang dari $0,05(0,00<0,05)$ sehingga dinyatakan bahwa minimal terdapat 1 variabel yang memiliki rata-rata rank yang berbeda.

\section{Faktor-Faktor yang Paling Dominan}

Faktor yang dominan atau paling menentukan berdasarkan hasil uji Kruskall Wallis , untuk memudahkan penilaian terhadap urutan dari faktor-faktor tersebut disampaikan pada Tabel 14 sebagai berikut.

Tabel 14. Urutan Faktor Yang Paling Dominan

\begin{tabular}{cccc}
\hline \multicolumn{4}{c}{ Ranks } \\
\hline Grup & N & Mean Rank \\
\hline \multirow{2}{*}{ Variabel } & Semangat Kerja & 32 & 84.94 \\
& Kerjasama & 32 & 84.81 \\
& Loyalitas Kerja & 32 & 61.00 \\
& Kecepatan Kerja & 32 & 27.25 \\
\hline
\end{tabular}

Dari Tabel 14 didapat perincian faktor dominan sebagai berikut.

- Semangat Kerja

Semangat kerja memiliki pengaruh yang sangat besar terhadap produktivitas para pekerja borongan dan berada di urutan pertama faktor yang paling dominan pada faktor yang mempengaruhi produktivitas pekerja borongan. Semagat kerja dapat diukur dengan tingkat absensi dan disiplin kerja. Pada umumnya mandor selalu memperhatikan pekerjanya untuk datang dan pulang tepat waktu, sehingga pekerjaan tidak tertunda. Ketidak hadiran seorang pekerja akan berpengaruh terhadap produktivitas kerja. Dengan adanya tingkat absensi yang baik maka dapat meningkatkan disiplin kerja. 


\section{- Kerjasama}

Kerjasama yang baik memiliki pengaruh terhadap produktivitas para pekerja borongan dan berada di urutan kedua faktor yang paling dominan pada faktor yang mempengaruhi produktivitas pekerja borongan. Dengan adanya saling berkontribusi tenaga maupun pikiran antara pekerja yang satu dengan yang lainnya, maka akan tercipta kerjasama yang baik dan dengan mengerahkan kemampuan masing-masing anggota tim secara maksimal, kerja sama akan lebih kuat dan berkualitas.

- Loyalitas Kerja

Loyalitas kerja yang baik memiliki pengaruh terhadap produktivitas para pekerja borongan dan berada di urutan ketiga faktor yang paling dominan pada faktor yang mempengaruhi produktivitas pekerja borongan. Dengan pemberian tanggung jawab dapat tercipta kerja sama yang baik dan dengan adanya taat peraturan maka pekerjaan akan cepat selesai. Loyalitas di identik dengan kesetiaan yang semestinya dilakukan dalam berbagai kondisi tanpa syarat dan tanpa mengharapkan adanya balasan. Loyalitas pekerja bukan hanya sekedar kesetiaan fisik yang tercermin dari seberapa lama seseorang bekerja, namun dapat dilihat dari seberapa besar pikiran, perhatian, gagasan, serta dedikasinya.

- Kecepatan Kerja

Kecepatan kerja yang baik memiliki pengaruh terhadap produktivitas para pekerja borongan dan berada di urutan terakhir faktor yang paling dominan pada faktor yang mempengaruhi produktivitas pekerja borongan. Dengan kecepatan kerja maka waktu yang tercapai akan lebih cepat dan kecepatan kerja maka akan berpengaruh pada hasil kerja. Tetapi hasil pekerjaan kebanyakan kurang bagus ataupun tidak memenuhi spesifikasi menurut para mandor. Itulah penyebab kenapa kecepatan kerja berada di rangking terbawah.

\section{KESIMPULAN}

Berdasarkan hasil analisis data dan pembahasan yang telah diuraikan pada Bab sebelumnya, maka dapat diambil kesimpulan bahwa faktor yang paling dominan berdasarkan hasil penelitian analisa uji Kruskall Wallis dalam faktor-faktor yang mempengaruhi produktivitas tenaga kerja berdasarkan sistem pemberian upah borongan di Kabupaten Sampang (studi kasus pembangunan ICU RSUD Kabupaten Sampang) adalah faktor Semangat Kerja (X3) dengan mean ranks 84,94. Semangat kerja memiliki pengaruh yang sangat besar terhadap produktivitas para pekerja borongan dan berada di rangking pertama faktor yang paling dominan pada faktor yang mempengaruhi produktivitas pekerja borongan. Semagat kerja dapat diukur dengan tingkat absensi dan disiplin kerja. Pada umumnya mandor selalu memperhatikan pekerjanya untuk datang dan pulang tepat waktu, sehingga pekerjaan tidak tertunda. Ketidak hadiran seorang pekerja akan berpengaruh terhadap produktivitas kerja. Dengan adanya tingkat absensi yang baik maka dapat meningkatkan disiplin kerja.

\section{SARAN}

Beberapa saran dalam menangani langkah pembangunan infrastruktur bisa disampakan sebagai berikut.

1. Dibutuhkan pekerja yang memiliki kemampuan dan keahlian, sehingga produktivitas tenaga kerja dapat dilaksanakan dengan baik dan terpenuhi.

2. Semua pekerja proyek harus dapat melakukan tugas dan kewajibannya sesuai dengan tanggung jawab masing-masing, agar pekerjaan bisa selesai tepat waktu.

3. Dalam penelitian ini hanya menggunakan 4 variabel yaitu: kecepatan kerja, kerjasama, semangat kerja, dan loyalitas pekerjaan. Untuk penelitian selanjutnya, perlu menambahkan variabel lain yang tidak masuk dalam penelitian saat ini. 


\section{DAFTAR PUSTAKA}

Anoraga, Panji (1998). Psikologi Kerja. Rinka Cipta. Jakarta.

Asmaroni, Dedy (2014). Analisa Keterlambatan Waktu Pelaksanaan Proyek Pembangunan Gedung Pemerintah Di Kabupaten Pamekasan. Universitas Madura. Pamekasan.

Basuki, I.R. \& Utomo, C. 2011. "Perbandingan Sistem Pemberian Upah Harian dengan Upah Borongan Terhadap Produktivitas Buruh Konstruksi pada Kontraktor di Surabaya". Jurnal Teknik, Vol. 10, No. 2.

Hasibuan, Malayu (2000). Manajemen Sumber Daya Manusia. Edisi Revisi. PT Bumi Aksara. Jakarta.

Hepiyanto, Rasio (2015). "Produktivitas Tenaga Kerja Borongan Dan Harian Pada Pekerjaan Plesteran (Studi Kasus Pada Pembangunan Hotel Ciputra World Surabaya - Jawa Timur)". Jurnal Teknik, Vol. 2, No. 2. Universitas Islam Lamongan...

Lazib, Thahiril, dkk. (2010). "Konsep Tentang Sistem Pemberian Upah Terhadap Produktivitas Buruh Konstruksi Di Surabaya". Jurnal Teknik, Vol. 9, No. 1.

Setiawan, Nugraha. 2005. Statistika Nonparametrik (Untuk Penelitian Sosial Ekonomi Peternakan). Universitas Pajajaran. Bandung.

Sedarmayanti (2001). Sumber Daya Manusia Dan Produktivitas Kerja. Mandar Maju. Bandung.

Suprayitno, H. \& Soemitro, R.A.A. (2018). "Preliminary Reflexion on Basic Principle of Infrastructure Asset Management". Jurnal Manajemen Aset Infrastruktur \& Fasilitas, Vol. 2, No. 1, Maret 2018, Hal. : 1-9.

Tanto, Dwi dkk. (2012). "Faktor-Faktor yang Mempengaruhi Produktivitas Pekerja Pada Pengerjaan Atap Baja Ringan di Perumahan Green Hills Malang". Jurnal Rekayasa Sipil, Vol 6, No. 1

Walpole, Ronald E (1995). Ilmu Pengantar Statistika. Edisi ke-3. PT. Gramedia Pustaka Utama. Jakarta.

Winarso, Kukuh (2015). Pengantar Statistika Industri 1. Pesona Karya Utama. Bangkalan. 